\title{
81:
}

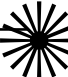

\section{A CIDADE-SANTUÁRIO DE APARECIDA: DEVOÇÃO, TURISMO RELIGIOSO E POLÍTICA}

- IVO FRANCISCO BARBOSA*

Resumo: A história de Aparecida e o culto que desenvolvera é sabido e amplamente abordado nas mais variadas literaturas. Sua função turístico-religiosa advém do descobrimento da imagem de Nossa Senhora da Conceição nas águas do rio Paraíba do Sul no ano de 1717. Com a construção do Santuário Nacional e a devoção impulsionada foram necessárias seguidas modificações no território religioso, de modo que as modificações aliassem conforto, espiritualidade, serviços e outros. É a partir dessa preocupação e da necessidade de agregar funcionalidade ao espaço da Igreja, portanto, que surge o Complexo Turístico Religioso, mais especificamente com a inauguração do Centro de Apoio ao Romeiro (CAR) em 1998. Se tem, neste momento, uma maior intencionalidade em adequar 0 espaço sagrado para além da devoção e intentar para uma forma caracterizada, mais especificamente, direcionada ao turismo religioso. O Complexo Turístico Religioso possui diversos atrativos de lazer ou espacialidades de lazer, mas destacam-se nesta pesquisa: o Centro de Apoio ao Romeiro (CAR), o Bondinho Aéreo, o Memorial da Devoção: Nossa Senhora Aparecida, o Presépio e o Caminho do Rosário. Da mesma maneira, o Santuário Nacional como eixo central e de controle, define uma territorialidade em função do sagrado. Do mesmo modo, dita de forma indireta o dinamismo espacial da cidade e a inserção de novos valores e significações entre o sagrado e profano, entre o peregrino religioso ao turista. O Santuário Nacional é um espaço de devoção e de busca pelo sagrado, em contrapartida, nos últimos anos tem sido palco de manifestações políticas, como A romaria à Aparecida por livre Lula e pela paz no Brasil realizada em 20 de maio de 2018. Deste modo, o presente artigo busca compreender, contextualizar e interpretar as ações no território religioso e sua transformação.

Palavras-chaves: Nossa Senhora Aparecida; Santuário Nacional, Turismo religioso, Lula.

\section{Introdução}

A cidade-santuário de Aparecida é conhecida pela devoção à Nossa Senhora da Conceição Aparecida, hoje, o território religioso também compreende um Complexo Turístico Religioso dotado de diversos atrativos de lazer. O presente artigo apresenta a transformação do espaço de devoção, suas novas funções voltadas para o turismo religioso, bem como um espaço de manifestações políticas. Por político, estamos nos 
referindo e contextualizando um momento específico de análise que ocorreu com A romaria à Aparecida por livre Lula e pela paz no Brasil realizada em 20 de maio de 2018.

Para remetermos a complexidade desta cidade-santuário, recorremos a historicidade de sua formação e transformação, do espaço sagrado primário ao espaço sagrado secundário e, ao mesmo tempo, analisamos as transformações com vista a sua modernização e acolhimento aos devotos e os turistas religiosos. Para compreender essa transformação adotou-se uma metodologia de estudo interpretativa, perceptiva, explicativa e participativa. Aliada ao uso de fontes bibliográficas, dados colhidos mediante a diálogos com representantes do Santuário Nacional e devotos, transcrição de áudios e material fotográfico. Este trabalho adotou também a observação participante nos eventos no campo de análise.

A confluência de agentes sociais ao logo de sua história de formação e constituição transformaram a cidade-santuário de Aparecida. A sua organização espacial se dá pela ação do devoto em direção a sua devoção, ao sagrado, e no papel do Santuário Nacional na implementação de obras que estão inseridas em uma perspectiva da hipermodernidade e em aspectos relacionados ao turismo religioso e que diversifiquem. Da mesma maneira, o devoto, o turista religioso e turista se direcionam à Aparecida em busca de outras demandas. Assim, esse território religioso compreende uma variedade de significados imbricados: religiosos, políticos e econômicos. É neste sentido que buscamos compreender e interpretar essas transformações e sua complexidade de significados e simbolismos.

\section{O espaço sagrado primário e espaço sagrado secundário - o Santuário Nacional}

A cidade de Aparecida é conhecida pela sua condição religiosa e pela prática do turismo religioso. Isto decorre do descobrimento da imagem de Nossa Senhora da Conceição nas águas do rio Paraíba do Sul no ano de 1717 e do seu culto. Ao logo de sua constituição como lugar de devoção este espaço foi sendo modificado e reestruturado, do local inicial de sua devoção, o lócus da hierofania, o espaço sagrado primário, ao atual Santuário Nacional, o espaço sagrado secundário (ELIADE, 1992).

A construção do primeiro espaço sagrado em 1745, no Morro dos Coqueiros pelo padre Vilella, vigário da Vila de Santo Antônio de Guaratinguetá, a atual Igreja Velha, demarca a força do ato devocional. Os relatos históricos dão conta de que com o aumento significativo no número de romeiros e de outros visitantes, tornara necessária a 
reformulação e ampliação da capela. A própria expansão do culto proporcionará o desenvolvimento de outras atividades voltadas ao atendimento dos devotos, já em meados de 1888, com pousadas e outros setores dirigidos ao acolhimento. Ao mesmo tempo, a religiosidade e a fama da Santinha ${ }^{1}$ atraem novos devotos e visitantes, culminando em novas remodelações, ampliações e controle das práticas religiosas (OLIVEIRA, 2001).

A compreensão do processo de construção desse novo espaço para a devoção e às atividades nas cidades que surgiram da função religiosa pressupõe discorrer de duas circunstâncias: a organização espacial e o papel do agente modelador (devoto, peregrino, turista religioso e turista) (ROSENDAHL, 1996, 2009). As cidades religiosas têm sua organização espacial regida pelo fluxo de devoto e a cidade de Aparecida tornara-se incongruente ao culto que desenvolvera, a ausência de infraestrutura diversas como estacionamentos, água potável, energia elétrica, falta de transporte e, principalmente, segurança para os devotos e para a realização das práticas devocionais. Essas dificuldades são preponderantes na ampliação e na mudança do espaço sagrado e facultaram na construção da Basílica Nova, o Santuário Nacional.

A monumentalidade do Santuário Nacional sinalizava para uma disparidade do município e da devoção que se desenvolvia em seus limites. A cidade se tornara limitada em sua forma urbana, insustentável para tal grandiosidade que se instalava e no atendimento à demanda. Nesse sentido, outras transformações foram efetivadas no Santuário Nacional no decorrer histórico, bem como novas espacialidades de lazer e turismo religioso. Por conseguinte, de modo a compreender essas transformações espaciais com vista a devoção e ao turismo religioso, utilizou-se as categorias de análise: (1) peregrinos; (2) romaria; (3) turista religioso; (4) turista; e (5) turista secular. Para tal, a introdução do conceito de turismo nas ciências sociais foi direcionada à temática do turismo religioso. Tal escolha ressalta o turista religioso dos outros referidos e a preocupação deste artigo é compreender nas mais variadas percepções e imbricações tais mudanças.

\section{As categorias de análise: o turismo e o turismo religioso}

O turismo é entendido como um ato/ação onde um indivíduo se põe em deslocamento de forma livre e espontâneo é o deslocamento que se dá fora de seu domicílio de origem (ALVES JÚNIOR, 2003). De acordo com Alves Júnior (2003, p. 26), 
"esta ação deve ter um período mínimo de vinte quatro horas, com pernoite". No entanto, consideramos está definição um tanto quanto fechada, tendo em vista que o ato de viajar está principalmente pautado na motivação, no tempo livre, no lazer e no conhecimento, que podem ocorrer com menor tempo de duração e não necessariamente pernoite.

A prática do turismo está inserida nas relações capitalista como uma atividade econômica. É uma atividade incorporada ao sistema capitalista que visa, sobretudo, o uso do tempo livre em seu sentido laborial (GAMA, A; SANTOS, N, 2008). Nesse sentido o indivíduo após sua carga de trabalho procura ocupar seu tempo livre com uma atividade que o remeta ao descanso e a necessidade de se recuperar para voltar ao ambiente do trabalho, isto é, a sua rotina diária (ALVES JÚNIOR, 2003). É dentro da perspectiva lançada que compete introduzir a ideia de turismo religioso como um ato de viajar, seja a lazer e com uma característica específica, a do fator motivacional religioso.

Segundo Steil (2003), o turismo religioso consiste na mudança de sentido do sagrado e de sua estruturação para aspectos da vida cotidiana, para os artífices mundanos e consumistas. De acordo com Steil (1999, p. 416), os termos turismo e peregrinação estão interligados e fazem "surgir no campo da religião uma estrutura turística de significados e valores que acaba [abarcando], mesmo que inconscientemente, a tradição peregrínica”, ao mesmo tempo que produz um outro evento, o turismo religioso. Por turismo religioso, os autores Arminda Souza e Marcos Corrêa (2000, p. 150), o identificam como sendo o turismo "motivado pela cultura religiosa", dotados de "conotação fortemente religiosa, ou ainda o conjunto de atividades que expressam sentimentos místicos ou suscitam fé”.

O turista religioso tem como anseio uma busca pelo lazer e prazeres de uma viagem, todavia, sem desvincular-se de sua fé que não é necessariamente seu motivo maior ao se pôr a viajar (ALVES JÚNIOR, 2003). Diferentemente do turista religioso e erroneamente vinculado a esta expressão, está o peregrino e romeiro, duas outras formas que buscam a satisfação espiritual, são igualmente viajantes, mas que possuem um objetivo básico, o imaterial, a fé, o sagrado.

\section{O peregrino e o romeiro}

A peregrinação cristã, "que data do século V, também é conhecida como romaria, pelo fato de consistir inicialmente na ida de devotos de suas localidades para Roma, visitar o túmulo de Pedro" (ROSENDAHL, 1996, p.56). Enquanto as peregrinações nos 
primórdios do Catolicismo inauguram segundo Santos (2007, p.61) "o costume de se pôr em marcha para pedir ou agradecer uma graça alcançada”. O romeiro pode ser entendido como sinônimo de peregrino "aquele que se sente estrangeiro, que está de passagem, em busca de um bem maior, superior à sua condição" (SANTOS, 2007, p. 61).

Definição semelhante é encontrada em Reesink (2007), para o qual o ato de peregrinação pode ser compreendido como o ato de busca, deslocamento, ou saída temporária de um lugar a outro. Em Alves Junior (2003), também se compreende desta definição, em que o peregrino, o romeiro e o visitante, partilham da mesma atribuição de um turista, onde ato de viajar e fazer uma jornada, parte-se de um ponto específico e retorna-se a um ponto de origem, e o objetivo básico desta caminhada é a busca ao sagrado e o partilhar de práticas típicas de uma peregrinação, como o sacrifício.

O peregrino e o turista religioso podem ser entendidos como similares, sobretudo, de acordo com Smith (1992) em comparticipar de três elementos operativos: o rendimento para a deslocação, tempo de lazer e a aprovação social da viagem, e até mesmo se utilizam das mesmas infraestruturas encontradas no deslocamento como nos pontos e locais turísticos. A diferenciação se dá no particular, nas relações motivacionais que fazem os indivíduos ou grupos se deslocarem de seus locais habituais, teoricamente, suas zonas de conforto. Exemplificação elucidativa desta linha tênue entre peregrino, turista religioso e turismo pode ser visualizada na Figura 1:

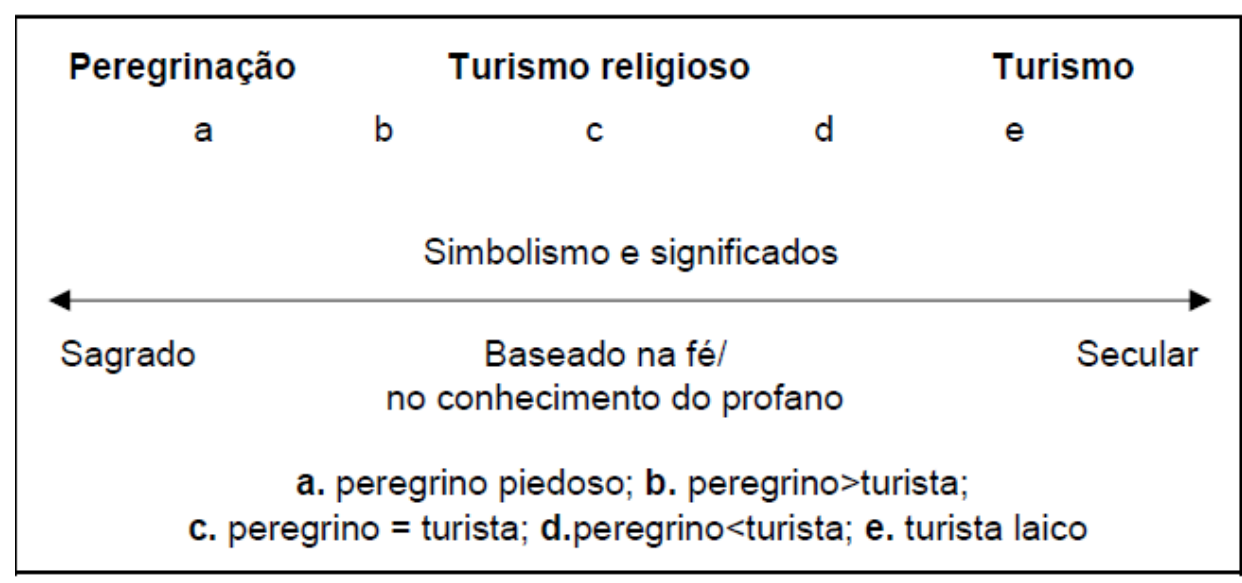

Figura 1 - O limiar Peregrino-Turista. Elaborado pelo autor e adaptado de Smith (1992) e Santos (2006, p. 8)

Como aponta Smith (1992) e Santos (2006), este esquema demonstra a linha tênue na diferenciação entre peregrino e turista. Há nesse trânsito uma variedade de motivações, desejos, formas de recreações e intencionalidades na determinação de um 
conceito que pode ser considerado de característica transitória, mas ao mesmo tempo particular, no que se refere ao indivíduo. Em Aparecida se observa o surgimento de diversos empreendimentos/obras pela Igreja Católica que transitam do espaço sagrado ao espaço profano, do peregrino religioso ao turista secular. Deste modo, apresentaremos as obras localizadas no Complexo Turístico Religioso e sua relação com os peregrinos e turistas.

\section{O Complexo Turístico Religioso: espacialidade de devoção e lazer}

Na cidade-santuário, no território religioso do Santuário Nacional e fora dele ${ }^{2}$, o devoto/peregrino, turista religioso e turista encontrará o Complexo Turístico Religioso que engloba: o CAR (Centro de Apoio ao Romeiro - ou shopping), o bondinho aéreo e o Morro do Cruzeiro, o presépio, a Cidade do Romeiro, o Memorial da Devoção e Caminho do Rosário ${ }^{3}$. Estes representam intenções e posicionamentos do Santuário Nacional em "acolher bem também é evangelizar", "surpreender e proporcionar momentos inesquecíveis de um jeito único e acolhedor”, mas há outras mensagens e valores que são preponderantes no seu cerne (BARBOSA, 2016). Esses valores e mensagens podem ser interpretados pela própria construção desses espaços e também pelo olhar do devoto.

A preocupação e a necessidade de agregar funcionalidade ao espaço da igreja e do entorno, portanto, remete a criação do Centro de Apoio ao Romeiro (Figura 2) (CAR), um local de consumo, inaugurado em 30 de maio de 1998 (BARBOSA, 2016). A criação do CAR compreende-se que representa uma particularidade desta cidade-santuário, de comercialização dos bens simbólicos relacionados ao espaço sagrado, onde o ato de devoção e de exercer a fé na sociedade moderna tem estado em concordância com o ato individualista do homem moderno (BARBOSA, 2016). Neste espaço o devoto/turista religioso/turista têm atrativos de lazer, praça de alimentação, posto médico, berçário, farmácia, cinema, aquário e entre outros.

Da premissa acima, clarifica-se que o turismo religioso é uma forma de turismo, ou seja, há um sentido comercial nele, mas nesses espaços o turista está em busca de um componente espiritual (SANTOS, 2006). Nesse novo espaço, então, esse devoto é um turista religioso que desembarca não apenas para a reflexão e busca de bênçãos, mas para a contemplação do espaço mercadoria. 


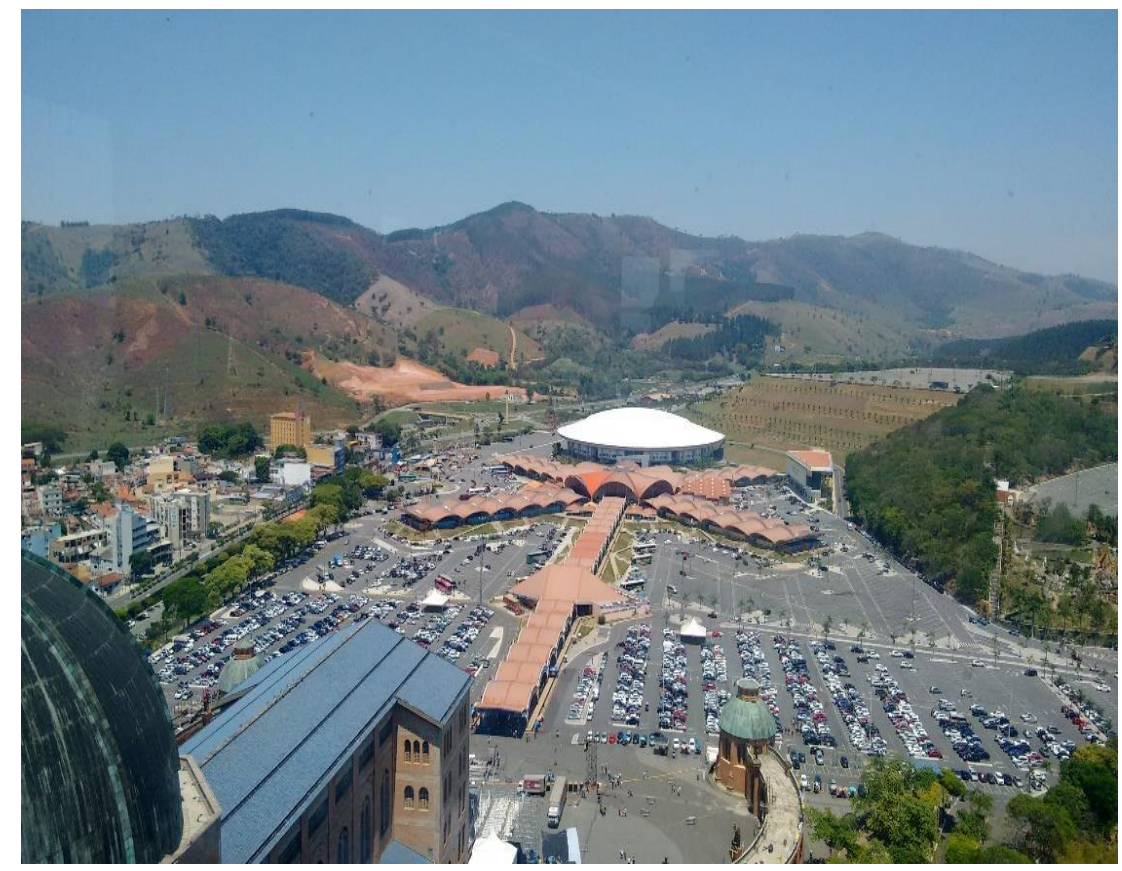

Figura 2 - Centro de Apoio ao Romeiro (CAR) em formato de cruz e, ao fundo, o Centro de Evento Padre Vitor Coelho de Almeida. Fonte: Ivo Francisco Barbosa (2018)

O Morro do Presépio (Figura 3) é outro atrativo de lazer e fé, inaugurado em 30 de novembro de 2013, possui 7.345 metros de comprimento, com peças em tamanho natural e feitas de cimento, localizado no pátio do Santuário. Em seu trajeto o devoto passará por estátuas e cenários que simbolizam o nascimento de Jesus e o encontro de Nossa Senhora nas águas do rio Paraíba do Sul. Para o Santuário Nacional, essas obras fazem parte de um processo contínuo de evangelização e de reviver a experiência da devoção. De acordo com alguns diálogos obtidos, trata-se de um local com "uma bela vista”, "um espaço de reza e reflexão" e para tirar "várias fotos”, sendo está uma característica da hipermodernidade, de contemplação do self e da cultura individualizada.

O Bondinho Aéreo (Figura 4) é uma obra icônica no Santuário Nacional, ela interliga a Basílica Nova ao Morro do Cruzeiro ${ }^{4}$, cruzando a rodovia Presidente Dutra, projetado pela empresa Bontur S/A, foi inaugurado oficialmente em 25 de junho de 2014 e custou aproximadamente 19 milhões de reais. Esses pontos-turísticos representam uma inserção direta do Santuário Nacional na produção e na reprodução do espaço urbano $^{5}$ e, segundo o seu representante, trata-se de uma demanda e necessidade do público que visita o templo, ao mesmo tempo, auxilia no deslocamento dos visitantes e proporciona uma nova motivação e lazer. 


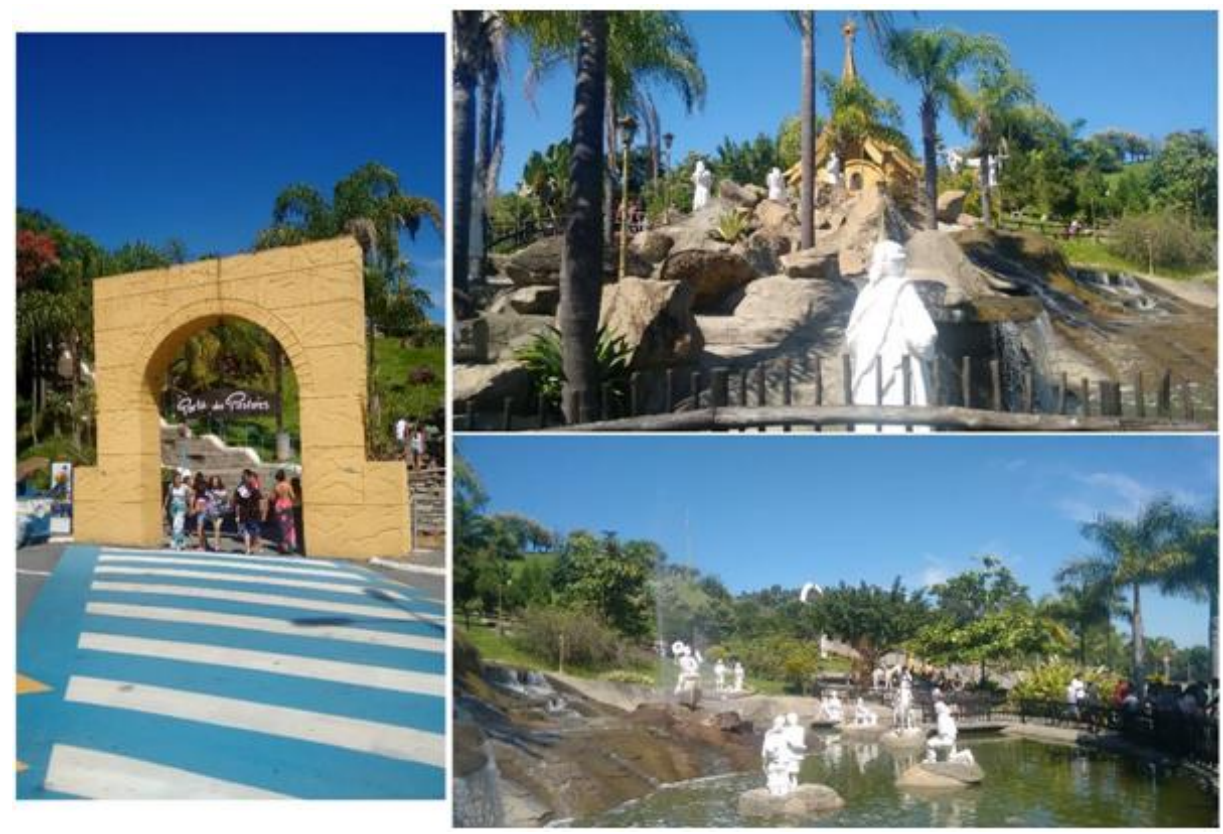

Figura 3 - Presépio. Fonte: Ivo Francisco Barbosa (2018).

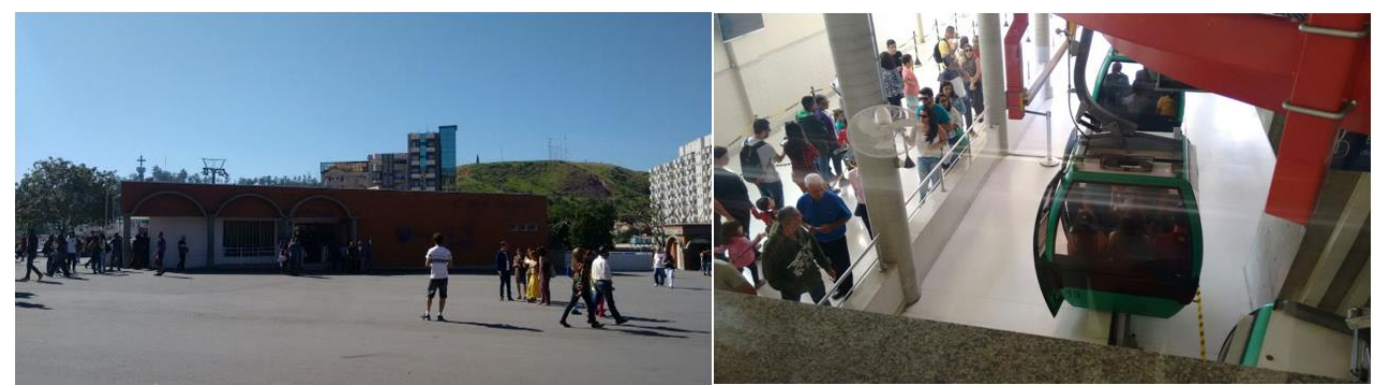

Figura 4 - Bondinho Aéreo. Fonte: Ivo Francisco Barbosa (2017).

As declarações dos representantes do Santuário Nacional em 2015 e $2018^{6}$, acerca das obras no território religioso e no seu entorno, podem ser interpretadas no que cerne a especialização do turismo religioso, ao adicionar novas demandas para o devoto, sobretudo, na prerrogativa de fixa-lo por maior tempo na cidade, proporcionando atividades de lazer.

Para as comemorações do Jubileu dos 300 anos, comemorado na semana da padroeira, 1 a 12 de outubro de 2017, o Santuário Nacional lançou diversas obras ${ }^{7}$ que simbolizam este momento, bem como a promoção de atividades e recursos turísticos que agreguem ao turismo religioso, como o Memorial da Devoção: Nossa Senhora Aparecida (Figura 5), inaugurado em 12 de fevereiro de 2016. Neste espaço há um cinema denominado Cine Padroeira, o Museu de Cera com mais de 60 personificações, o Cantinho dos Devotos Mirins, espaço para exposições e uma loja de artigos religiosos. 
Para o Santuário Nacional, o Memorial da Devoção tem como atributos e intenções aliar multimídia e simbolismo em uma experiência sensorial. Esta definição pode ser vista na síntese apresentada em seu site ${ }^{8}$

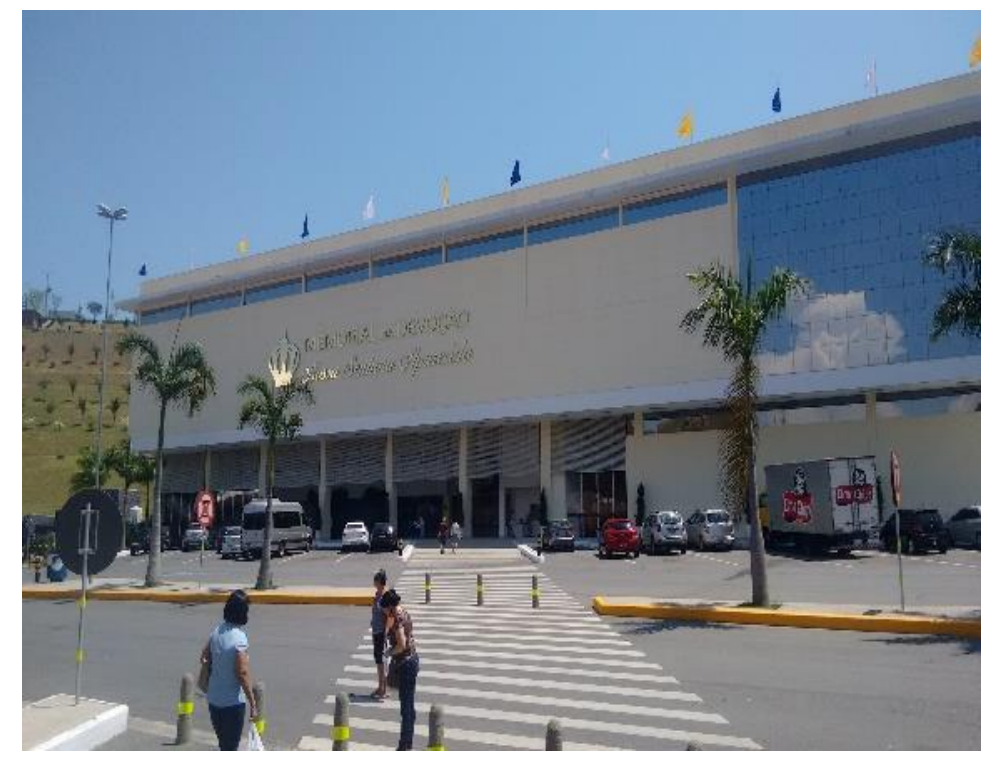

Figura 5 - Memorial da Devoção: Nossa Senhora Aparecida. Fonte: Ivo Francisco Barbosa (2017)

Interpreta-se que o Memorial da Devoção, assim como outras obras no Santuário Nacional e no seu entorno, representa intenções e posicionamentos que como defendido pela instituição possuem como proposição a ação de "acolher bem também é evangelizar" - "Surpreender e proporcionar momentos inesquecíveis de um jeito único e acolhedor". Ainda com respeito a declaração obtida de um representante do Santuário Nacional ${ }^{9}$, este diz que as obras "tem por objetivo único a evangelização, seja por meio de construções físicas (no caso de obras), seja por meio dos projetos sociais ou pela acolhida. Tudo aqui converge para o anúncio da Boa Nova de Jesus Cristo”. Embora, outras mensagens, valores e significados, atribuídos nesses espaços voltados ao turismo religioso podem ser interpretadas, como as relacionadas aos devotos e suas impressões quanto as obras realizadas pelo Santuário Nacional.

A Cidade do Romeiro (Figura 6) é uma materialidade no espaço urbano projetada pelo Santuário Nacional para acolhimento dos romeiros, peregrinos, turistas religiosos e turistas, mas também como um centro turístico-religioso e comercial. Esse produto turístico, a aproximadamente 700 metros do Santuário Nacional de Aparecida, foi inaugurado no dia 15 de dezembro de 2012 e lançado com investimento parcial de 60 milhões de reais provenientes do Banco Nacional de Desenvolvimento Econômico e 
Social (BNDES ${ }^{10}$. O empreendimento possui dois hotéis, o Hotel Rainha do Brasil e Hotel San Diego Express, lojas e estabelecimentos comerciais.
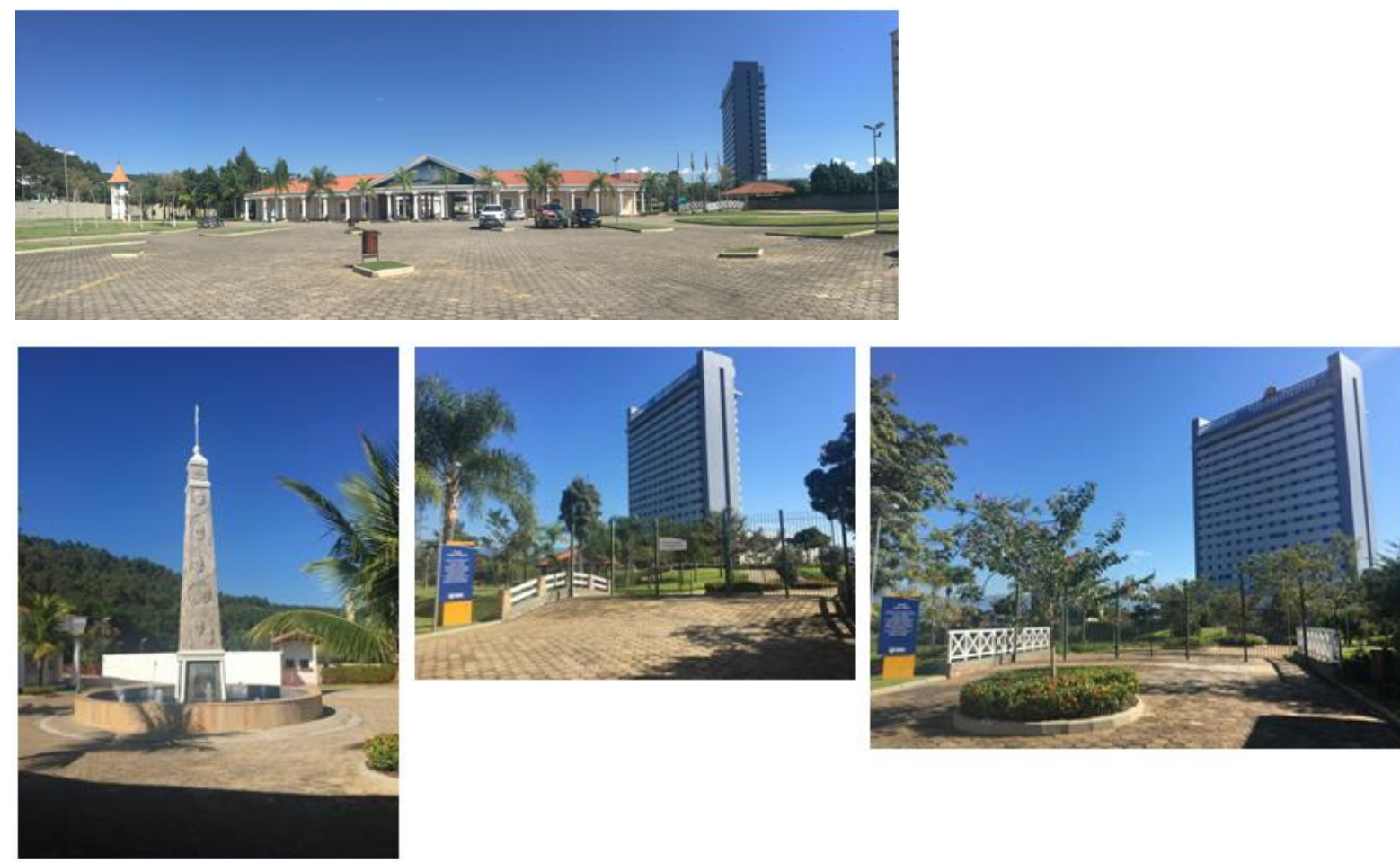

Figura 6 - Cidade do Romeiro. Foto: Ivo Francisco Barbosa (2019)

Em diálogos realizados com os devotos em outubro de 2017 e em maio de 2018, eles nos reportaram que as obras são importantes pois representam “a casa da Mãe e está deve sempre estar bonita”, ao mesmo tempo, relataram que tais locais estão incluídos em seus roteiros de viagem, seja por parte das paróquias que compõem a organização territorial da Instituição Religiosa Católica Apostólica Romana, bem como são parte da política de manutenção do fluxo de peregrinos aos templos religiosos. Da mesma maneira, considera-se que para o peregrino o valor comercial de determinada obra/empreendimento não é o objeto principal e ponto de interesse. As obras correspondem "necessidades” para glorificação de Nossa Senhora Aparecida.

No levantamento de informações junto aos devotos, outras condições foram mencionadas quanto as excursões de agências de turismo, de acordo com os diálogos, as agências têm fomentado o roteiro turístico religioso pelo Vale do Paraíba (Cachoeira Paulista, Guaratinguetá e Aparecida), também conhecido como o Circuito Turístico Religioso $^{11}$. Os roteiros incluem a visitação as espacialidades de lazer no território religioso, o que remete a uma fidelização e a efetivação deste projeto. Todavia, destacamse que essas são algumas informações provenientes de diálogos e não podem 
corresponder uma totalidade embora demonstrem o sucesso da prática. O Santuário Nacional é um território religioso, um espaço de turismo religioso e, ao longo de sua formação, sempre foi palco político no Brasil. Assim, apresenta-se na próxima parte uma manifestação simbólica e política ocorrida em 2018.

\section{A cidade-santuário: território religioso e político}

Ao longo da historicidade desse espaço, os agentes políticos sempre estiveram presentes em doações de terras, na proclamação como Padroeira e Rainha do Brasil, na expansão do Santuário Nacional, na Ditadura Militar e na difusão do culto mariano (OLIVEIRA, 2001; MOURA, 2003; ALVAREZ, 2014). Em 2018, ano decisivo no cenário político brasileiro, o Santuário Nacional demonstrou interesse e preocupação com os rumos políticos nacionais, sobretudo com a intolerância política e religiosa. Da mesma maneira, os candidatos, os partidos políticos e outros movimentos veem neste lugar sagrado, no espaço sagrado, o local propício para manifestações e para associarem às suas imagens. Exemplo desse momento foi A romaria à Aparecida por Lula livre e pela paz no Brasil, onde o político e o religioso se chocaram e apresentaram nuances e delimitações. Onde a perspectiva e importância da manifestação religiosa aliada a política se fez presente, com atuações, discursos, intolerância política e atos de devoção carregados de significados e simbolismos. São ações que dimensionam e compactuam que o político e o religioso estão presentes, são conflitantes e interpretativos.

A análise da experiência vivida no ato político inicia-se desde o trajeto do Rio de Janeiro a cidade de Aparecida, em um ônibus fretado pelo partido dos trabalhadores. $\mathrm{O}$ ponto de partida foi o Teatro Municipal às seis horas da manhã. Neste trajeto algumas percepções, interpretações e opiniões foram ouvidas. Em síntese, a grande maioria dos entrevistados se diziam ser católicos e devotos de Nossa Senhora Aparecida, todavia, havia um motivo maior nesta ida, o ato político, a defesa de Lula, Luís Inácio Lula da Silva e, em um outro lado, rezar contra a violência no Brasil. Contudo, as falas, os discursos e os ideais eram centrados nos posicionamentos políticos e injustiças cometidas por juízes para com o ex-presidente. Ressalta-se que para uma romaria com o intuito de ir até Aparecida e rezar pelos supracitados, em nenhum momento rezas, cânticos ou práticas religiosas foram feitas durante a viagem. Claro, não se pode atribuir esta condição a todas as romarias daquele dia. 
É importante frisar que antes da própria viagem e do ato religioso em Aparecida, as redes sociais já eram inflamadas com a possibilidade da realização de uma missa no território religioso e que caberia ao Santuário Nacional barrar tal situação, conforme alguns comentários ${ }^{12}$ e páginas contrárias a realização da missa com aqueles propósitos anunciados pela presidenta do partido dos trabalhadores, Gleisi Hoffman (Figura 7) e pelo coordenador Gilberto de Carvalho ${ }^{13}$ :

A missa não é um ato político-partidário, nada disso. Vai ser um ato católico, o pessoal vai lá para rezar, não é pra fazer debate, nem pregação. É para rezar pelo Lula, nós estamos muito felizes porque está havendo uma grande participação, em Minas Gerais tem mais de 30 ônibus se organizando e também em São Paulo, no Vale do Paraíba, nós queremos lotar a basílica para que o Lula sinta o apoio do povo e para que esse povo possa se expressar.

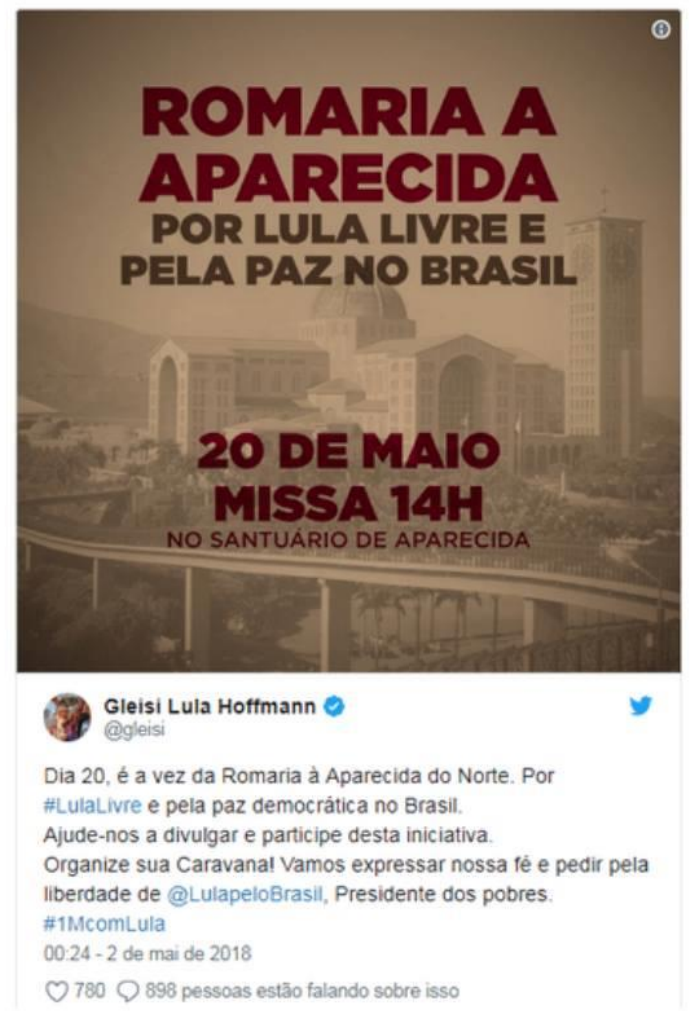

Figura 7 - Anúncio da Romaria à Aparecida Fonte: Twitter Gleisi Hoffmann (2018) 
A chegada em Aparecida ocorrera às 10 horas da manhã e o ponto de concentração foi a Igreja Velha, o primeiro templo oficial para a Santa. Neste local, as primeiras hostilidades e conflitos tiveram início, embora menos tensos. A todo momento algum falante ao microfone, discursos e falas eram proferidas para os devotos lulistas. No mar de camisas vermelhas com o rosto de Lula e da Santa irrompiam na concentração, nesta concentração algumas rezas e cânticos eram proferidas. Ali, o religioso e político se entrelaçaram, o profano e o sagrado, a Basílica Velha, davam uma outra áurea e simbolismo para o ato (Figura 8).

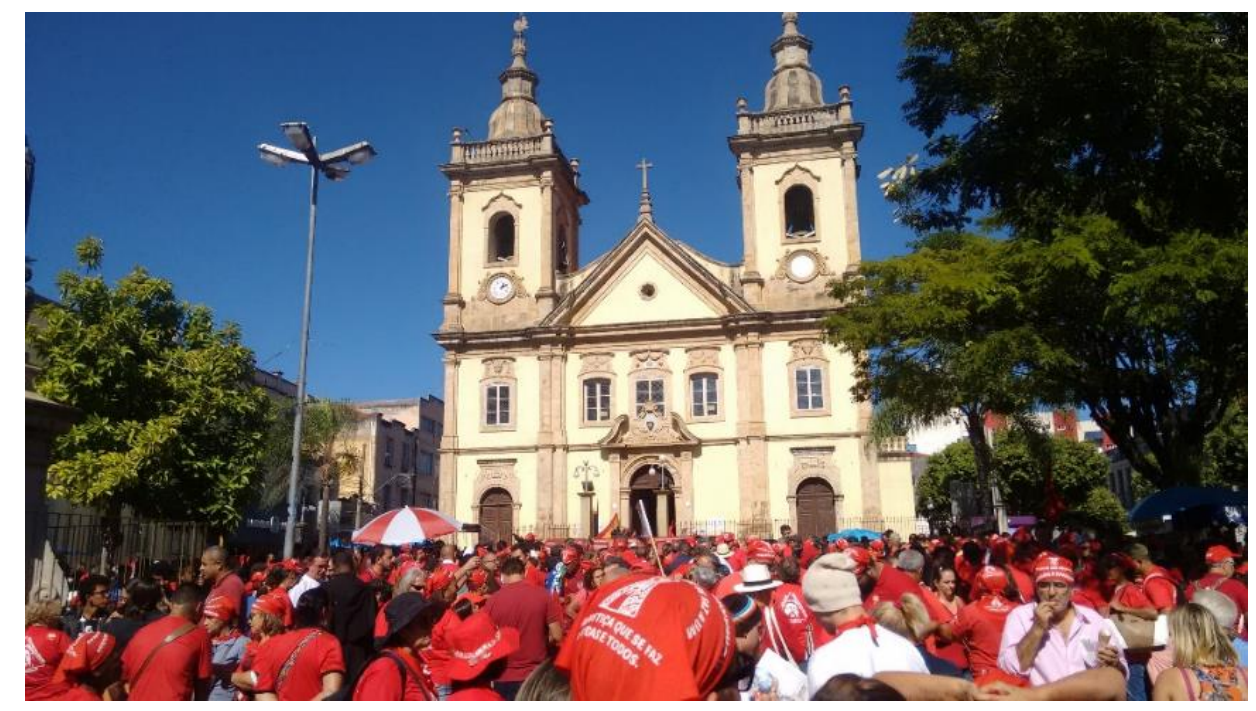

Figura 8 - Concentração da romaria na praça Nossa Senhora Aparecida.

Foto: Ivo Francisco Barbosa (2018)

Na história de Aparecida e de construção desta cidade-santuário, o político esteve presente desde o início no pequeno povoado da Vila de Santo Antônio de Guaratinguetá, na Igreja Velha, no Santuário Nacional e na romaria político partidária. Os agentes sociais - Igreja Católica e os políticos - concatenaram acordos, interesses e condições que alicerçaram a propagação da religiosidade e naquela romaria outros acordos, nuances e intenções foram previamente acordadas e que merecem uma análise e interpretação.

A romaria concentrou-se nos arredores da Igreja Velha e a todo momento um puxador do ato assumia o centro e proferia palavras de ordem, das quais destacam-se as palavras proferidas pelo coordenador Gilberto de Carvalho que apresentou o acordo feito com o Santuário Nacional, entre os representantes Dom Orlando Brandes, Arcebispo da Arquidiocese de Aparecida e o Padre João Batista de Almeida, Reitor do Santuário Nacional. No acordo, os manifestantes deveriam respeitar o espaço sagrado e 
o território religioso, deixando evidente o poder da instituição o Santuário Nacional e as estratégias de convívio no espaço. Este momento foi extremamente simbólico e visível, os manifestantes devotos ou devotos lulistas ao trespassarem o limite entre o acesso a passarela da fé, por recomendação do presidente do PT e do Santuário Nacional, ficara expressamente proibido a manifestação de palavras de ordem, o hasteamento de bandeiras ou qualquer tipo de ação que não fosse devocional religiosa. Embora, a desobediência civil é um estado natural dos seres humanos e tal situação foi observada na passarela da fé (Figura 9), no território religioso e no espaço sagrado, sobretudo, na missa

A romaria foi organizada pelo Movimento Mineiro de Fé e Política e pelo Fórum Político Inter-religioso, ambos de Minas Gerais, mas também contou com a presença de grupos da região do Vale do Paraíba, grande São Paulo e Rio de Janeiro. Notadamente, observou-se a presença de políticos, seja por serem devotos marianos, devotos lulistas ou por interesses majoritariamente eleitoreiros, desses podemos destacar a presença de lideranças; o vereador Eduardo Suplicy; o presidente do PT de São Paulo, Luiz Marinho; o presidente do PT do Rio de Janeiro, Washington Quaquá, entre outros. 


\section{5:}
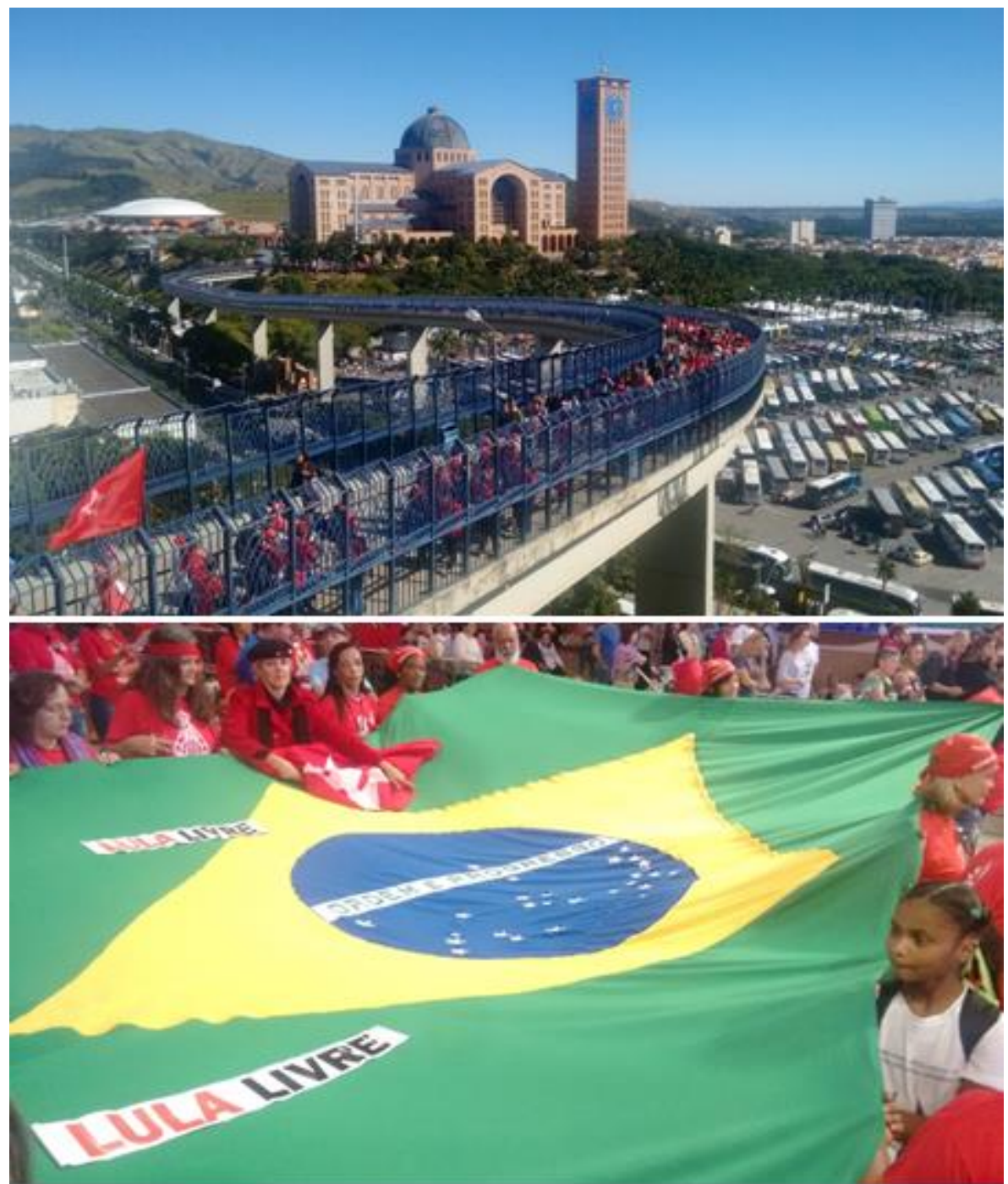

Figura 9 - Romaria na Passarela da Fé e devotos lulistas na missa.

Foto: Ivo Francisco Barbosa (2018)

A missa representou a idealização do movimento e sua proposta, mas também a experiência devocional. Embora os discursos dos leigos e do celebrante correspondem nesta primeira análise o ápice da romaria e que podem ser amplamente interpretados e reinterpretados. Ressalta-se que antes da realização da missa e as palavras proferidas pelo celebrante e leigos são interpretativas e até contraditórias se observar a nota oficial emitida pelo Santuário Nacional com respeito ao evento:

O Santuário Nacional de Aparecida é um espaço sagrado que acolhe todos os filhos e filhas de Nossa Senhora Aparecida, sem distinção;

Da mesma forma, também é uma Casa que se coloca contra toda e qualquer utilização do seu espaço para fins políticos ou ideológicos; 
Com base nos valores éticos e cristãos, o Santuário Nacional entende que o momento atual é propicio de reflexão e protagonismo do cidadão ao que tange às escolhas eleitorais, por isso, sob qualquer se posiciona ou se posicionará em favor de quaisquer líderes políticos refutando toda e qualquer iniciativa que queira utilizar-se do Altar da Eucaristia para fins de promoção individual ou partidária;[...]

Ainda que o comunicado oficial emitido no dia 3 de maio de 2018 explicita que o Santuário Nacional é contra a utilização do seu espaço para fins políticos, observou-se, invariavelmente, o contrário no espaço sagrado, sobretudo, no momento em que o celebrante proferiu no sermão as intenções de reza por Lula e pela paz no Brasil. Esses trechos podem ser vistos nesta transcrição do áudio da missa:

Nós viemos aqui para rezar, por que acreditamos na força da oração. [ [...] Então meus irmãos e minhas irmãs, bem-vindos, nós estamos aqui para rezar, eu estava olhando aqui, a gente sempre deixa no cantinho do altar esse cálice e eu vou levantar para todo mundo ver, aqui a gente coloca as intenções das pessoas. Olha, quanta gente pediu para que nós rezássemos, tanta gente passa por aqui, deixa seu nome, sua causa e o seu pedido. Porque acredita na força da oração. Eu quero aqui fazer uma saudação muito carinhosa e muito especial para todos vocês que vieram rezar por Lula e pela paz no Brasil.

Naturalmente, o respeito pelo espaço sagrado e a não manifestação de cunho político partidária em sua grande maioria foi respeitosa. No entanto, com a intenção da reza sendo proferida, observou-se alguns gritos com as palavras: "Lula Livre", "Fora Temer" e "golpistas e fascistas". Tais palavras, em um outro momento foram rechaçadas pelo celebrante padre João Batista com um "shut up", em inglês, "cala a boca" ou "fiquem quietos".

As manifestações dos devotos pelo ex-presidente Lula e os discursos interpretativos dos religiosos atingiram uma outra percepção e intenção com a leitura do leigo:

Pela paz e fraternidade do povo brasileiro, para que Nossa Senhora Aparecida nos abençoe e que saibamos conviver como irmãos mesmo nas divergências, nas diferenças, eliminando toda forma de intolerância e ódio entre nós. Rezemos ao senhor. [...] Pelo ex-presidente Luís Inácio Lula da Silva, para que Nossa Senhora Aparecida o abençoe e lhe dê muitas forças, e que se faça a verdadeira justiça para que, o quanto antes, ele possa estar entre 
nós, construindo com o nosso povo um projeto de país, que semeia a justiça e a fraternidade. Rezemos ao Senhor! [grifo do autor].

Os devotos em êxtase aplaudiram, choraram e se manifestaram com palavras de apoio ao ex-presidente Lula, ao mesmo tempo, pairava no ar um olhar de incredulidade e dúvidas quanto aos discursos proferidos pelos religiosos. Está percepção foi posteriormente confirmada com alguns manifestantes ao final da missa e no retorno ao Rio de Janeiro, muitos reportaram que não estavam acreditando no que ouviram, "a Igreja”, "o Santuário Nacional estaria apoiando o presidente". Nesse misto de interpretações e desejos por partes dos devotos lulistas, um outro sentimento era preponderante, a alegria de estar na casa da Mãe e o sentimento de paz. A fé em Nossa Senhora Aparecida e na verdadeira justiça para com o ex-presidente ganhara uma outra relação e a confiança na liberdade era sentida...

A missa celebrada no dia 20 de maio de 2018 e a mensagem que lhe foi atribuída soou para além do território religioso e as respostas e repercussões não demoraram. Em época da hipermodernidade o poder das mídias sociais e de sua propagação exercem um papel fundamental, principalmente, em encurtar discursos e faze-los atingir àqueles que querem ouvir ou não. Dessa maneira, as falas e os atos realizados naquele dia soaram e atingiram um público contrário à romaria para o Lula e o Santuário Nacional prontamente respondeu aos fiéis. Em nota ${ }^{14}$, do dia 23 de maio, o celebrante da missa e o Santuário Nacional vieram tentar consternar a situação como pode-se ler:

Permanecei no meu amor! (Jo 15,9)

Saudação e Bênção a todos,

Nós, Dom Orlando Brandes, Arcebispo da Arquidiocese de Aparecida; Pe. José Inácio de Medeiros, Superior Provincial dos Missionários Redentoristas da Província de São Paulo; Pe. João Batista de Almeida, Reitor do Santuário Nacional de Aparecida, através desta nota, nos dirigimos ao povo brasileiro e, em especial, aos devotos de Nossa Senhora Aparecida. Manifestamos nosso profundo pesar pelo desapontamento que causamos a todos. Pedimos perdão pela dor que geramos à Mãe Igreja, aos fiéis e às pessoas de boa vontade.

Em nossa Ação Pastoral, o Santuário Nacional, a Arquidiocese de Aparecida e a Congregação Redentorista não defendemos uma posição político-partidária, que é contrária ao Evangelho. Estamos sim, em comunhão com o Magistério e com a Doutrina Social da Igreja. 
Contudo, eu, Pe. João Batista, Reitor do Santuário Nacional, manifesto meu pesar e peço o perdão de todos que se sentiram ofendidos pela maneira como conduzi a celebração da missa das 14 horas, do último dia 20 de maio. Quero reafirmar meu compromisso com a Arquidiocese de Aparecida, com a Congregação do Santíssimo Redentor, com os colaboradores e voluntários do Santuário Nacional e com todos os que bebem dessa fonte de restauração de vidas.

Encerrando, renovamos nosso pedido de perdão e confiamo-nos à oração de todos. Pois, com a Mãe Aparecida, "tudo o que é quebrado pode ser restaurado". Queremos continuar fazendo do Santuário Nacional a Casa da Mãe de todo o povo brasileiro.

Interceda por todos nós a Mãe Aparecida, Rainha e Padroeira do Brasil, a Mãe da Misericórdia.

Padre João Batista de Almeida

Reitor do Santuário Nacional

Padre José Inácio de Medeiros

Provincial da Unidade Redentorista de São Paulo

Dom Orlando Brandes

Arcebispo de Aparecida [grifo nosso]

Dentro dessas diversas condições e situações o Santuário Nacional procurou consternar a tensão. Na esfera digital, na página da rede social A12, os devotos não partidários pediam a renúncia do reitor e nessa estratégia de política depois do fato acontecido, o Santuário Nacional com a nota, intenta deixar o âmbito da esfera político partidária e o ódio semeado entre a direita e a esquerda fora do espaço sagrado. Enquanto para os fiéis da romaria política e os do PT, precisam continuar a devoção pelo expresidente Luís Inácio Lula da Silva e contra a violência no Brasil.

Está romaria teve cunho e viés político partidário, pode-se enumerar outros eventos que ocorrem no Santuário Nacional, na casa da Mãe Aparecida, onde a esfera política e o religioso se encontraram. Apenas como um exemplo, no dia 10 de abril de 2016, o Movimento Legislação e Vida esteve no espaço sagrado, embora em menor número que a romaria petista, para defender o que eles apontam como sendo: "Por uma Igreja livre do PT e dos comunistas". Da mesma maneira que a realizada por grupos lulistas, os devotos direitistas hastearam bandeiras e entoaram palavras de ordem. Dentro dessas conjecturas de manifestações tanto de direita e de esquerda, tem-se o espaço sagrado como lugar de devoção, prioritariamente, todavia, em uma sociedade 
difusa, com problemas sociais agravados e dividida, o território religioso é também mais um campo para a exposição política e ideológica.

\section{Considerações Finais}

A cidade-santuário de Aparecida perpassará por um processo histórico de formação facultada pela devoção à Santa. Hoje, o Santuário Nacional é o maior responsável pelas diretrizes da devoção, contrariamente ao início, no período do espaço sagrado secundário, a Igreja Velha. Com a sua política institucional religioso, centrada no "acolher bem também é evangelizar", o grupo redentorista tem ampliado e diversificado a espacialidade de lazer e devoção, na medida que suas obras não somente estão relacionadas aos aspectos turísticos e comerciais, mas sim em seu maior interesse, a fé e, nesta, sua resistência e dinâmica.

O espaço sagrado, o Santuário Nacional, com o caldeirão e efervescência política instalada nos últimos anos, tornou-se mais um espaço de manifestação e de ocupação, no sentido de fazer valer os seus discursos e suas respectivas ideologias. Em contramedida, a instituição Igreja, tenta abraçar seus devotos das mais variadas ideologias e ao mesmo tempo lidar com essa linha tênue.

Ao realizar tal missa e nos sermões situar-se pelo ideal social e deslizar em algumas posições, o Santuário Nacional procura rapidamente posicionar-se em defesa do ideal da devoção e não desmitificar a imagem apartidária. Da mesma maneira, ciente da sua influência para com os devotos católicos, o Santuário Nacional, a Igreja Católica, sabe que deve se posicionar e estar aberta ao cenário político, ideológico e religioso atual e tem se estruturado e assumido papel importante nesta seara.

Analisar e interpretar as transformações no território religioso e político é compreender que as respostas não são prontamente dadas e tão pouco representam em sua plenitude verdades absolutas, correspondem processos de construção e entendimento de partes, mas que corroboram para o discernimento dessa tão emblemática cidade-santuário, palco de devoção e de um momento político impar no Brasil. 


\section{NOTAS}

* Doutorando em Geografia pela Universidade do Estado do Rio de Janeiro, Mestre em Geografia pela Universidade Federal Fluminense, Especialização em Gestão Ambiental pela Universidade Federal de São Carlos, Bacharel/Licenciado em Geografia pela Universidade Sagrado Coração. Bolsista Faperj e Pesquisador do NEPEC em Rede. ivo_francisco@hotmail.com

${ }^{1} \mathrm{O}$ adjetivo destacado foi uma das denominações carinhosas informadas nos diálogos com os devotos

${ }^{2} \mathrm{O}$ Morro do Cruzeiro, a Cidade do Romeiro e o Caminho do Rosário estão situados fora do território religioso do Santuário Nacional.

${ }^{3}$ Este último recém-inaugurado não será abordado nesta pesquisa.

${ }^{4}$ O Morro do Cruzeiro, antes de ser identificado como ponto turístico-religioso na cidade de Aparecida, era almejado pelos redentoristas como um importante ponto para a construção do novo Santuário, em meados de 1939 (BRUSTOLONI, 1980).

${ }^{5}$ Barbosa (2016) apresenta a configuração espacial urbana dos arredores do Morro do Cruzeiro.

${ }^{6}$ Informações dadas em entrevista realizada em 2015 e em entrevista gravada em 2018.

${ }^{7} \mathrm{O}$ vocábulo obra é simbólico e assume um papel importante no discurso do Santuário Nacional. Sua transmissão está nos discursos, nas missas e sermões, nas entrevistas concedidas e na catequese, como pode ser visto no personagem Tijolinho, parte do projeto de evangelização infantil do Santuário Nacional. ${ }^{8}$ Disponível em: <http://www.memorialdadevocao.com.br/>. Acesso em: 09 de nov. 2017.

${ }^{9}$ Entrevista cedida por e-mail. Padre João Batista, 2018.

10 Disponível em: <http://economia.estadao.com.br/noticias/geral,aparecida-investe-na-cidade-doromeiro-imp-,580818>. Acesso em 04 de dez. 2017.

${ }^{11}$ Circuito Turístico Religioso Católico. Disponível em:

$<$ https://eventos.cancaonova.com/cobertura/circuito-turistico-religioso-do-vale-e-inaugurado/>.

Acesso em 30 de set. de 2018.

12 Matérias vinculadas na mídia digital. Disponível em:

<https://www 1.folha.uol.com.br/poder/2018/05/santuario-de-aparecida-critica-seu-uso-politico-aposgleisi-convocar-romaria-por-lula.shtml>; <https://www.oantagonista.com/brasil/santuario-condenaromaria-de-gleisi-por-lula/>. Acesso em: 27 de set. 2018.

${ }^{13}$ Disponível em: <https://www.redebrasilatual.com.br/politica/2018/05/2018vamos-lutar-com-muitoamor-para-que-lula-volte-ao-nosso-meio2019-afirma-ex-ministro>. Acesso em 29 de set. 2018.

${ }^{14}$ Disponível em: <http://www.a12.com/santuario/imprensa/releases/nota-de-reparacao>. Acesso em: 29 de maio de 2018.

\section{REFERÊNCIAS BIBLIOGRÁFICAS}

ALVAREZ, R. A biografia da santa que perdeu a cabeça, ficou negra, foi roubada, cobiçada pelos políticos e conquistou o Brasil. 1.ed. São Paulo: Ed.Globo, 2014.

ALVES JÚNIOR, N. As peculiaridades do Turismo Religioso e a Peregrinação: universo humano fundamentado no turismo. In: Turismo Religioso: Caminhos da Fé. Fortaleza: SENAC, 2003.

BARBOSA, I. F. A produção do espaço urbano em Aparecida: agentes e processos. Dissertação (Mestrado em Geografia), Universidade Federal Fluminense, Campos dos Goytacazes, 2016. 
BRUSTOLONi, J. Construção da Nova Basílica: Documentário e Notícias (1955-1988). Aparecida, Mimeo, 1980 .

ELIADE, M. O sagrado e o profano. Tradução Rogério Fernandes. São Paulo: Martins Fontes, 1992.

GAMA, A; SANTOS, N. Lazer: da libertação do tempo à conquista das práticas. Ed. 1. Coimbra: Imprensa da Universidade de Coimbra, 2008.

LIPOVETSKY, G. e SERROY, J. A cultura mundo, resposta a uma sociedade desorientada. Tradução: Maria Lúcia Machado. São Paulo: Companhia das Letras, 2011.

OLIVEIRA, C. D. M. de. Basílica de Aparecida: Um templo para a cidade-mãe. $1^{\text {a }}$. ed. v. 1. São Paulo: Olho D'água, 2001.

ROSENDAHL, Z. Espaço e religião: uma abordagem geográfica. 1. ed. Rio de Janeiro: UERJ, NEPEC, 1996. Hierópolis: O sagrado e o urbano. 2. ed. Rio de Janeiro: Ed. UERJ, 2009.

SANTOS, L. DOS. A cor da santa: Nossa Senhora Aparecida e a construção do imaginário sobre a padroeira do Brasil. In: VAGNER, G. da S. (org), Imaginário, cotidiano e poder. São Paulo, 2007: Summus/Selo Negro. Coleção Memória Afrobrasileira. vol 3. 87-108.

SANTOS, M. da G. S. P. Turismo e Território - Estudo Geográfico de Fátima. Editora Princípia, $1^{\text {a }}$ Ed. Portugal, 2006.

SMITH, V. L. The quest in guest. Annals of Tourism. Research, n. 19, p 1-17, 1992.

SOUZA, A. M.; CORRÊA, M. V. Turismo: conceitos, definições e siglas. Manaus: Valer, 2000.

STEIL, Carlos. A. Peregrinação e Turismo: o natal em Gramado e Canela. Teocomunicação, Porto Alegre, v. 29, n.125, p. 413-432, 1999

Peregrinação, Romaria e Turismo Religioso: Raízes Etimológicas e Interpretações Antropológicas. In: ABUMANSUR, E. S. (org). Turismo religioso: ensaios antropológicos sobre turismo e religião. Campinas: SP, Papirus, 2003. 


\title{
THE SANCTUARY CITY OF APARECIDA: DEVOTION, RELIGIOUS TOURISM AND POLICY
}

\begin{abstract}
THE HISTORY OF APARECIDA AND THE CULT SHE HAD DEVELOPED IS WELL KNOWN AND WIDELY APPROACHED IN THE MOST VARIED LITERATURE. ITS TOURIST-RELIGIOUS FUNCTION COMES FROM THE DISCOVERY OF THE IMAGE OF OUR LADY OF THE CONCEPTION IN THE WATERS OF THE PARAÍBA DO SUL RIVER IN 1717. WITH THE CONSTRUCTION OF THE NATIONAL SHRINE AND THE DEVOTED IMPETUS, IT WAS NECESSARY TO FOLLOW CHANGES IN THE RELIGIOUS TERRITORY, SO THAT THE MODIFICATIONS ALLY COMFORT, SPIRITUALITY, SERVICE AND OTHERS. IT IS FROM THIS CONCERN AND THE NEED TO ADD FUNCTIONALITY TO THE SPACE OF THE CHURCH, THEREFORE, THAT THE RELIGIOUS TOURIST COMPLEX EMERGES, MORE SPECIFICALLY WITH THE INAUGURATION OF THE ROMEIRO SUPPORT CENTER (CAR) IN 1998. THERE IS NOW A GREATER INTENTIONALITY IN ADJUSTING THE SACRED SPACE BEYOND DEVOTION AND INTENT IN A CHARACTERIZED WAY, MORE SPECIFICALLY, DIRECTED TO RELIGIOUS TOURISM. THE RELIGIOUS TOURIST COMPLEX HAS SEVERAL ATTRACTIONS OF LEISURE OR LEISURE SPATIALITIES, BUT WE HIGHLIGHT IN THIS RESEARCH: THE ROMEIRO SUPPORT CENTER (CAR), THE AERIAL CABLE CAR, THE MEMORIAL OF DEVOTION: OUR LADY APARECIDA, THE NATIVITY SCENE AND THE WAY OF THE ROSARY. LIKEWISE, THE NATIONAL SHRINE AS THE CENTRAL AND CONTROL AXIS DEFINES A TERRITORIALITY IN FUNCTION OF THE SACRED. SIMILARLY, IT INDIRECTLY DICTATES THE SPATIAL DYNAMISM OF THE CITY AND THE INSERTION OF NEW VALUES AND MEANINGS BETWEEN THE SACRED AND THE PROFANE, BETWEEN THE RELIGIOUS PILGRIM AND THE TOURIST. THE NATIONAL SHRINE IS A PLACE OF DEVOTION AND THE SEARCH FOR THE SACRED, IN CONTRAST, IN RECENT YEARS HAS BEEN THE SCENE OF POLITICAL MANIFESTATIONS, SUCH AS THE PILGRIMAGE TO APARECIDA BY FREE LULA AND PEACE IN BRAZIL HELD ON MAY 20, 2018. THUS, THE PRESENT ARTICLE SEEKS TO UNDERSTAND, CONTEXTUALIZE AND INTERPRET THE ACTIONS IN THE RELIGIOUS TERRITORY AND THEIR TRANSFORMATION.
\end{abstract}

KEYWORDS: OUR LADY APARECIDA; NATIONAL SANCTUARY, RELIGIOUS TOURISM, LULA.

\section{EL SANTUARIO DE APARECIDA: DEVOCIÓN, TURISMO RELIGIOSO Y POLÍTICA}

RESUMEN: LA HISTORIA DE APARECIDA Y EL CULTO QUE DESARROLLÓ ES BIEN CONOCIDA Y AMPLIAMENTE ABORDADA EN LA MÁS VARIADA LITERATURA. SU FUNCIÓN TURÍSTICO-RELIGIOSA PROVIENE DEL DESCUBRIMIENTO DE LA IMAGEN DE NUESTRA SEÑORA DE LA CONCEPCIÓN EN LAS AGUAS DEL RÍO PARAÍBA DO SUL EN 1717. CON LA CONSTRUCCIÓN DEL SANTUARIO NACIONAL Y EL ÍMPETU DEVOTO, FUE NECESARIO SEGUIR LOS CAMBIOS EN EL TERRITORIO RELIGIOSO, PARA QUE LAS MODIFICACIONES ALIADO CONSUELO, ESPIRITUALIDAD, SERVICIO Y OTROS. ES DE ESTA PREOCUPACIÓN Y DE LA NECESIDAD DE AGREGAR FUNCIONALIDAD AL ESPACIO DE LA IGLESIA, POR LO TANTO, SURGE EL COMPLEJO TURISSTICO RELIGIOSO, MÁS ESPECÍFICAMENTE CON LA INAUGURACIÓN DEL CENTRO DE APOYO ROMEIRO (CAR) EN 1998. AHORA HAY UN MAYOR INTENCIONALIDAD EN AJUSTAR EL ESPACIO SAGRADO MÁS ALLÁ DE LA DEVOCIÓN Y LA INTENCIÓN DE UNA MANERA CARACTERIZADA, MÁS ESPECÍFICAMENTE, DIRIGIDA AL TURISMO RELIGIOSO. EL COMPLEJO TURÍSTICO RELIGIOSO TIENE VARIAS ATRACCIONES DE OCIO O ESPACIALIDADES DE OCIO, PERO DESTACAMOS EN ESTA INVESTIGACIÓN: EL CENTRO DE APOYO ROMEIRO (CAR), EL TELEFÉRICO, EL MEMORIAL DE LA DEVOCIÓN: NUESTRA SEÑORA APARECIDA, EL BELÉN Y EL CAMINO DEL ROSARIO ASIMISMO, EL SANTUARIO NACIONAL COMO EJE CENTRAL Y DE CONTROL DEFINE UNA TERRITORIALIDAD EN FUNCIÓN DE LO SAGRADO. DEL MISMO MODO, DICTA INDIRECTAMENTE EL DINAMISMO ESPACIAL DE LA CIUDAD Y LA INSERCIÓN DE NUEVOS VALORES Y SIGNIFICADOS ENTRE LO SAGRADO Y LO PROFANO, ENTRE EL PEREGRINO RELIGIOSO Y EL TURISTA. EL SANTUARIO NACIONAL ES UN LUGAR DE DEVOCIÓN Y LA BÚSQUEDA DE LO SAGRADO, EN CONTRASTE, EN LOS ÚLTIMOS AÑOS HA SIDO ESCENARIO DE MANIFESTACIONES POLITIICAS, COMO LA PEREGRINACIÓN A APARECIDA POR LULA LIBRE Y LA PAZ EN BRASIL CELEBRADA EL 20 DE MAYO DE 2018. ASÍ, EL PRESENTE ARTÍCULO BUSCA COMPRENDER, CONTEXTUALIZAR E INTERPRETAR LAS ACCIONES EN EL TERRITORIO RELIGIOSO Y SU TRANSFORMACIÓN.

PALABRAS CLAVE: NUESTRA SEÑORA APARECIDA; SANTUARIO NACIONAL, TURISMO RELIGIOSO, LULA. 